\title{
Subject and longitudinal use of books by Indian space technologists*
}

\author{
M.S. Sridhar
}

\begin{abstract}
A $20 \%$ stratified sample of books of the Indian Space Research Organisation's (ISRO) Satellite Centre (ISAC) Library were examined to record over 14,000 outside borrowings. The use of these books is analysed with frequency tables to pinpoint unused, least used and highly used books. Studies are made also of the relative use of books in different subject groups, longitudinal use over time, subject use of unused and highly used books and distribution of use over age and year of acquisition of the books. The paper concludes by discussing the extent of use of books at the ISAC Library and providing findings concerning collection development and weeding processes.
\end{abstract}

KEYWORDS: Use studies, user studies, space technologists, use of books, longitudinal studies, special libraries, subject-wise use of books

\section{INTRODUCTION}

A study of outside use of books of the ISAC library based on a $20 \%$ stratified collection sample was made in 1983. An earlier paper $^{1}$ presented, in addition to results and observations at the broad level, the background of the study, data collection method and limitations. Two thousand and ninety one sample books accounting for 14,674 loans since end of 1972 when the ISAC library began and 3,158 loans to 708 borrowers during the last ten months (January/March to October/December 1983) are analysed in this paper by the number of times loaned, by subject, by year of publication and by year of acquisition. In addition, a longitudinal study is made of how books were borrowed during the ten months prior to the survey is being carried out as compared with the cumulative use from end 1972 to date.

\section{FREQUENCY DISTRIBUTION OF USE OVER NUMBER OF BOOKS}

Table I presents a frequency distribution of use over number of books. Nearly $27 \%$ of the books in the sample were not loaned even once. ${ }^{2}$ The balance, $73 \%$ of all books in the collection, could be deemed to belong to the "core collection". ${ }^{3}$ The Kent study suggests that "if a minimum of two uses were arbitrarily established expost-facto as a criterion for a costeffective acquisition program, 54.2\% of titles purchased in 1969 would not have been ordered; if three uses, then $62.5 \%$ would not have been ordered." ${ }^{4}$ As against this, $40.8 \%$ and $49.9 \%$ of books in the ISAC library can be thought of as non-cost-effective acquisitions with two uses and three uses as threshold criteria respectively.

It may be seen from Table I that $4.5 \%$ of the books account for $25.2 \%$ of borrowings (in the Kent's study by contrast $4.06 \%$ of items accounted for $20 \%$ of transactions); $9.9 \%$ of the books contributed $44.9 \%$ of total use (as against $11.59 \%$ of items meeting $40 \%$ of use in 
Subject and longitudinal use of books by Indian space technologists

the Kent study) and $20.6 \%$ of the books account for $82.7 \%$ of use (as against $42.41 \%$ of items producing $80 \%$ of transactions in the Kent study). ${ }^{5}$ Thus a smaller part of the collection has accounted for a much larger part of use in ISAC library. Table I, when plotted as a graph in which the cumulative percentage of books is shown against the cumulative percentage of use, produces a parabolic or asymptotic or zipfian type distribution of values.

\section{RELATIVE USE OF BOOKS IN DIFFERENT SUBJECT GROUPS}

Space science and satellite technology are heterogeneous, multidisciplinary subjects. As such, knowing the composition of different subjects in a collection and their respective use is of value, as Martin and Lancaster suggest. ${ }^{6}$ Table II shows the subject use of books. Also presented in the table, for comparative purposes, are the approximate percentage of the total number of users specialising in the subject under review, the length of shelf space in feet that the subject occupies, the approximate percentage of total book stock and the percentage of sample in each subject. A word of caution about the specialisation of users. The figures given are only approximate. They are based on what appears in the users' educational qualifications and not on their present area of work. While working out this percentage, 681technical staff as of January 1982 were considered; non-technical staff members were not included in the calculation. Hence, subject groups such as the social sciences, the natural sciences in general, arts, literature, etc., have been marked NA (not applicable). Subject groups such as astronomy and astrophysics form part of physics; telecommunication is a specialisation of many in the electronics groups. Thus, specialisation data should not be regarded as strictly accurate data but only indicative.

The percentage of use is substantially greater than the percentage of the sample which is more or less the same as the percentage of total stock in the case of D (mathematics), $\mathrm{N}$ (energy), $\mathrm{O}$ (electronics), $\mathrm{P}$ (telecommunication), Q (mechanical engineering) and $\mathrm{W}$ (manufactures). Of these $\mathrm{D}, \mathrm{N}, \mathrm{O}, \mathrm{P}$ and $\mathrm{Q}$ are given substantial specialist usage. As expected, more books are borrowed in the field of specialisation of users than in other fields. The only exception to this apart from generalities ( $A$ ) occurs in physics ( $E$ and $F$ ), and this might be explained by the fact that physics is fundamentally a pure science and that very few scientists and engineers in the Centre other than a small groups of physicists themselves are engaged in research in this field, although $8.8 \%$ of technical staff members have physics as their academic specialisation. Further, the percentage of stock in physics is more than double the percentage of users. 
The last column of Table II shows use per linear foot of shelf used. To arrive at this the actual use is multiplied by five, the sample factor, and divided by the linear shelf length in feet. While the average use per linear foot of shelf is 69.2, usage varies from 22 to 128.3. Subject groups B (social sciences, etc.), D (mathematics), K (engineering and technology in general), O (electronics), Q (mechanical engineering), $U$ (management) and X (arts, etc.) undergo a greater than average use per linear foot of shelf.

It may be noted here that the number of books per linear foot in the case of social sciences (B), management $(U)$ and arts $(X)$ is naturally greater than that in the case of the science and engineering fields. Thus, the usage per linear foot of shelf space confirms, more or less, the relatively greater use made of some subjects than of others. Least use per linear foot of shelf occurs in subject groups A (generalities), $\mathrm{H}$ (geology, etc.), M (energy) and T (agriculture, etc.) One reason for low use of books in group $A$ is laid to the fact that bibliographies and library science books are kept separately in broken sequence from others in $A$, and some of them are subjected to restricted access.

Frequency scores have been tabulated individually for each subject group. Considering books loaned 31 or more times as "highly used" and those for which no record is available as "never used", Table III indicates the number of such highly used and never used books in different subject groups. The samples in subject groups D,E,F,N.Q.P,S,V,W and X contain at least one highly used book. Of these groups $D, N, O, P, Q, S$ and $W$ contain greater than average number of highly used books (i.e., 4.5). On the other hand, subject groups $A, F, H, I, J, K, L, M, S, T$ and $W$ have more than average age number (i.e., 26.6) of never used books. While the percentage of non-hits (i.e., never used books) is quite high in A,J,K,M and $\mathrm{T}$, while have no highly used books, groups $\mathrm{F}, \mathrm{S}$ and $\mathrm{W}$ have both never used and highly used books.

\section{LONGITUDINAL USE OF BOOKS}

How books are used during the latest ten months as compared to their cumulative use is discussed in this section. Table IV presents a picture of the longitudinal use of books of different subject groups. As can be seen from the table, a positive increase in use of books occurred in the case of medical sciences (J), engineering and technology in general $(\mathrm{K})$, material science (L), electronics (O), aeronautics and space vehicles (S), and manufactures (W). The intensity of increase is high in $\mathrm{W}(+7.6 \%)$, marginal in $\mathrm{O}(+2.0 \%)$ and negligible in case of $\mathrm{J}$ $(+0.1 \%), \mathrm{K}(+0.3 \%)$ and $\mathrm{L}(+0.1 \%)$. In all the remaining subject groups there is a decline in use. In most cases, however, this decline is marginal or negligible. 


\section{FREQUENCY DISTRIBUTION OF USE OVER AGE (YEAR OF PUBLICATION) OF BOOK}

It is generally believed that use of library documents declines with age in a negative exponential pattern. In other words, frequency of use is a function of the age of the document. However the actual date (or year) of acquisition of the document plays a significant role, and this matter is treated in the next section. Knowledge of the composition of library stock by age (year of publication) as well as by year of acquisition along with some indication of relative use is important in planning for future library acquisitions.

Table V illustrates the use recorded books by year of publication. Since the time survey was begun in 1983, many 1982 and 1983 publications were yet to be acquired, processed and released for use, the use of such books is naturally underrepresented.

The distribution of sample documents over year of publication gives some idea about currency of the collection. It is apparent that books published in 1978 are most heavily represented in the collection (11.9\%). Twelve percent of books in the library were published earlier than 1971. In other words, $88 \%$ of the books in the library are published within the last 12 years and 60.1\% published since 1975.

On examination of the use of books of different ages indicates that the percentage of total use for each year is more or less the same as the percentage of the sample. The average use per book increases steadily as the years recede. It must be borne in mind of course that books published in earlier years have had the chance to circulate more number of times if acquired immediately after publication and considerable increase in number of users (and hence number of borrower tickets.) There is no clear evidence that use correlates with the age of the books. ${ }^{7}$

Adding another dimension, i.e., the subject of the document, to the use data of books, the frequency distribution of use over age of books in different subject groups was examined. It was observed that the mode year of publication of books changes from one subject to other. Table VI presents the mode year of publication of books in different subject groups. For example the mode year of publication of items in applied science and technology, electronics, mechanical engineering, aeronautics and space vehicles is ahead of the mode year of publication of the entire sample (1978). On the other hand, the mode year of publication of books in mathematics, geology, medical science, generalities, 
Subject and longitudinal use of books by Indian space technologists

social sciences, energy, etc., is behind the mode year of publication of the entire sample. Subjects with bimodal distributions in Table VI are not too reliable as the absolute size of samples in these groups is quite small. Though no decisive inference can be drawn from this it may be noted that in certain disciplines such as electronics only the latest books are sought by users.

Since the library has existed for only about 10 years and no weeding has yet been done, every subject has the same chance of having 1978 as the mode year of publication. It was found, for example, that 37 books out of 252 sample books in manufactures (W) were published in 1978. And that in the case of physics (F), books published during the 1950s, 1960s, 1970s are recorded relatively more use than similar books in other groups and even the latest books in physics itself. Finally, none of the sample books in applied science and technology in general (I) was published before 1975.

\section{FREQUENCY DISTRIBUTION OF USE OVER YEAR OF ACQUISITION OF BOOK}

It appears that how soon after publication a document is acquired has a stronger effect on total use of the document than does the year of publication of the document. As Line and Sandison indicate, "the pattern of usage over time appears quite different if the standing point is taken as the publication date or three or four years after." ${ }^{8}$

Table VII presents data concerning distribution of use over year of acquisition of books. Also presented for comparative purposes is the total number of items acquired during the year. As in the previous section, data about documents acquired during 1982 and 1983 should be viewed with caution.

The percentage of sample items and the percentage of items acquired in a particular year are more or less the same. The representativeness of the sample is thus confirmed. Moreover, the average use per book increases more uniformly, steadily and steeply in the case of use over year of acquisition than in the case of use over age (of Table V). Except for 1974 and 1978 in which a marginal fall in average use per book takes place, all other years have a uniformly increasing average use per book.

The number of books acquired per year is not uniform, although the number acquired during 1978 and later (except for 1981) is more or less constant. The largest number of books was acquired in 1978, and the second largest in 1979. 
Frequency distributions of use over year of acquisition of book in different subject groups are also tabulated and examined. Some observations on these distributions follow. The mode year of acquisition of all the subject groups except social sciences (1982), natural sciences in general (1980), mathematics (1973), astronomy and astrophysics (1980), electrical engineering (1973), chemical technology (1980) and manufactures (1982) is close to 1978. In mathematics and electrical engineering the largest number of books was acquired during 1973. This might explain why the mode year of publication in mathematics appears in Table VI as 1972. In the other subject groups mentioned above the mode year of acquisition is 1980 or later, and hence naturally their mode year of publication is 1977 or later (see Table VI).

Although the sample books have been found to be representative, relatively more use (or more accurately average use per year) is made of books procured during 1978-1980. One of the obvious reasons for this as mentioned earlier, is an increase in user strength and a general predilection for novelty of stock. ${ }^{9}$

\section{RESULTS AND OBSERVATIONS}

To recapitulate, books in the subjects of specialisation are given relatively greater use than others. The average use per linear foot of shelf space is 69.2 , and this varied from 22 to 128.3, depending upon subject. In an analysis of data on longitudinal use, it is found that books in certain subject such as electronics and manufactures have shown an increase in percentage of use in recent months.

Nearly $27 \%$ of books are never borrowed and about $21 \%$ account for $83 \%$ of total use. In some subjects like generalities, geology, and medical sciences, the percentage of never used books is higher than the overall percentage of such books in the sample. Subjects such as physics, aeronautics, space vehicles and manufactures have both never used and highly used books.

Nearly $88 \%$ of books in the library were published in the last 12 years, and $60 \%$ were published since 1975. Use did not clearly correlate with age of books. The mode year of publication of books in subject groups such as electronics, mechanical engineering, aeronautics and space vehicles is later than the mode year of publication of the entire collection. Books published between 1950 and 1970 are recorded relatively more use in case of physics than in other groups. 
Subject and longitudinal use of books by Indian space technologists

The average use per book increases more uniformly, steadily and steeply in the case of

use over year of acquisition than it does in the case of use distribution over age of book. The sample has been found to be adequate in terms of year of acquisition. The mode year of acquisition of all subjects except mathematics and electrical engineering coincides more or less with the mode year of acquisition of the entire sample.

A further study of correlating use of books with various user characteristics and a rigorous statistical test of the data are being done separately. By and large, books have been fairly well used in the ISAC library. The study assisted the library in determining how use of books is distributed among different subject groups and in pinpointing which books in the collection are highly used and which receive little or no use. It is expected that this information will prove useful in future collection development activities.

\section{NOTES AND REFERENCES}

1. M. S. Sridhar, "A case study of lent out use of documents in a special library" (to be published).

2. During seven years and two months period at Pittsburgh University Library $48.37 \%$ of the collection did not circulate at all. See Allen Kent et al. Use of library materials: The University of Pittsburgh study. New York: Marcel Dekker Inc., 1979, Pp. 12-13. Under 55\% of books had no recorded use during a nineteen-month period at Newcastle Upon Tyne Polytechnic Library. See C. Harris "A comparison of issues and in library use of books", Aslib proceedings, 29(3) March 1977, p.119.

3. Kent defines an item as being in the core collection if it circulates externally one or more times. Allen Kent et al. Idem. p.49.

4. Ibid, p.10.

5. Ibid, p.38. In the case of the Harris study loans account for just over $45 \%$ of stock. C. Harris, Idem, Pp.119-120.

6. John Martyn and F. Wilfred Lancaster. Investigative methods in library and information science: An introduction. Virginia: Information Resources Press, 1981, p.78.

7. A previous study on the effect of age upon book use revealed a similar result. See M.S.Sridhar, "Document reservation pattern in a special library: A case study", Library science with a slant to documentation, 20(1) March 1983, Pp. 39-48.

8. Maurice Line and A. Sandison, "Obsolescence and changes in the use of literature with time", Journal of documentation, 30(3) Sept 1974, p. 51.

9. Harris study showed that "... a greater proportion of material acquired in 1972 was used than of that acquired prior to 1972 (and) ... material acquired after 1972 is more heavily used than that material acquired during 1972, reflecting a general presence for novelty of stock." See C. Harris, Idem, p.121. 
Subject and longitudinal use of books by Indian space technologists

YABLE I

FREQUENCY DISTRIBUTION OF USE OVER NUMBER OF BOOKS

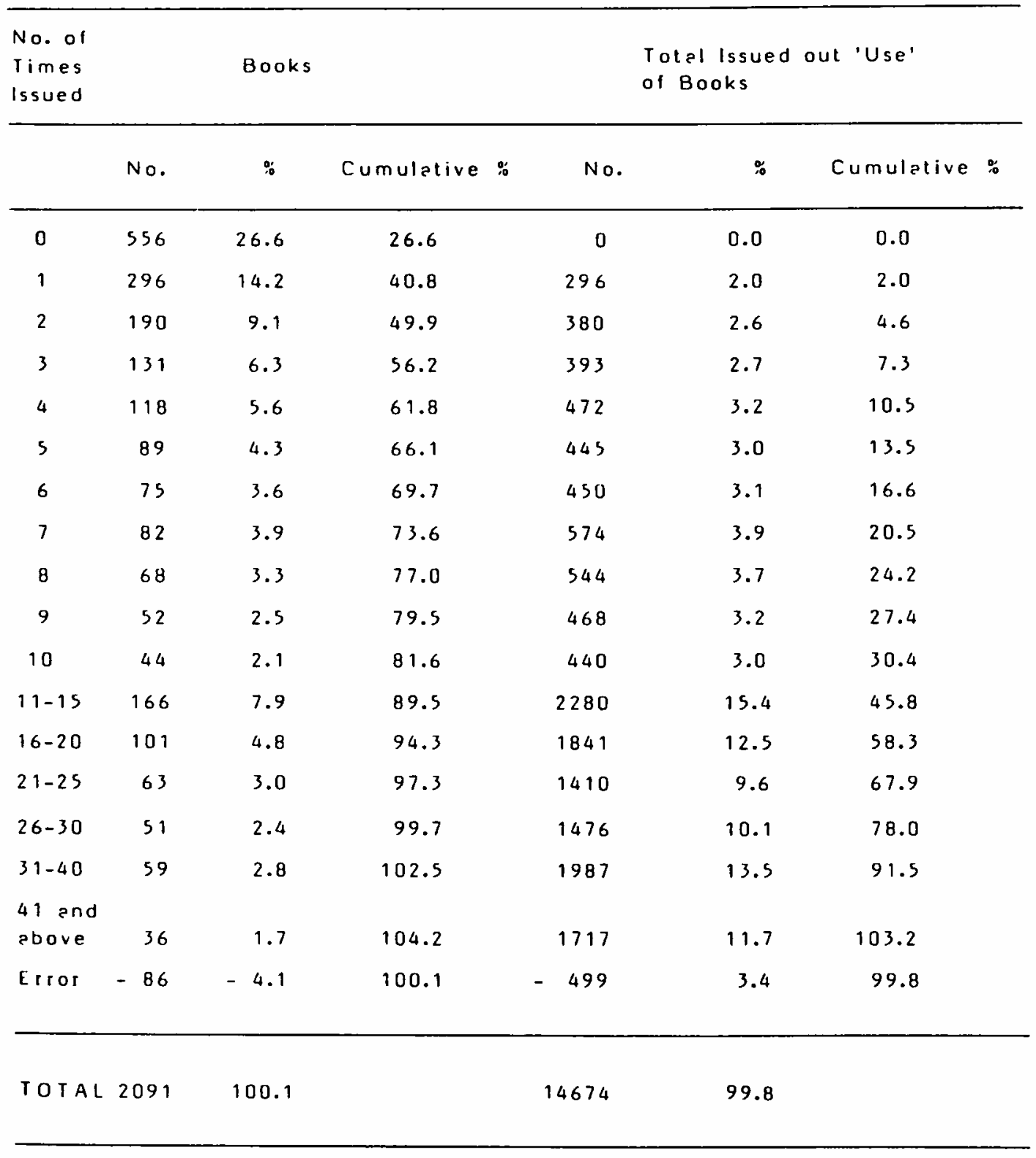


Subject and longitudinal use of books by Indian space technologists

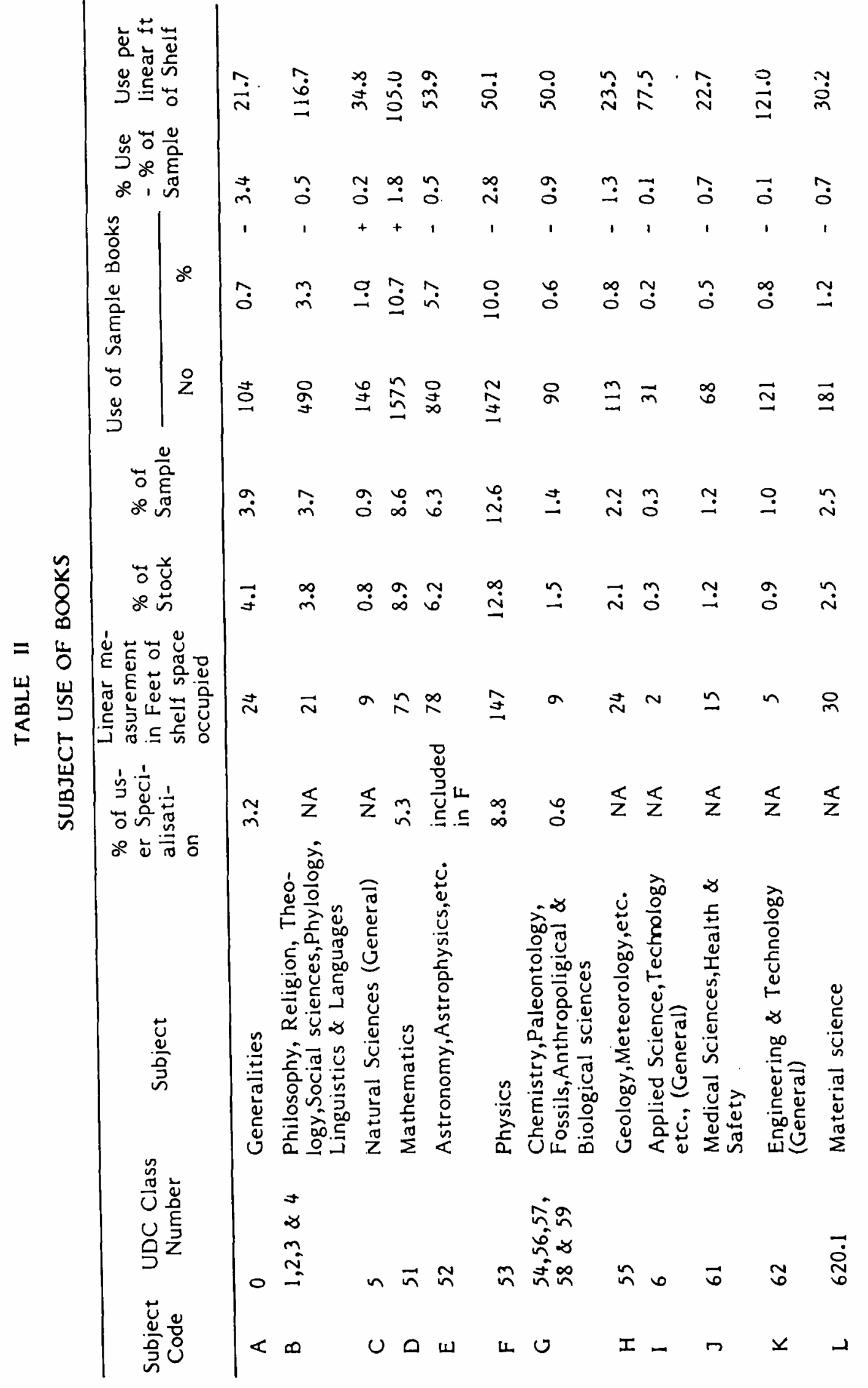




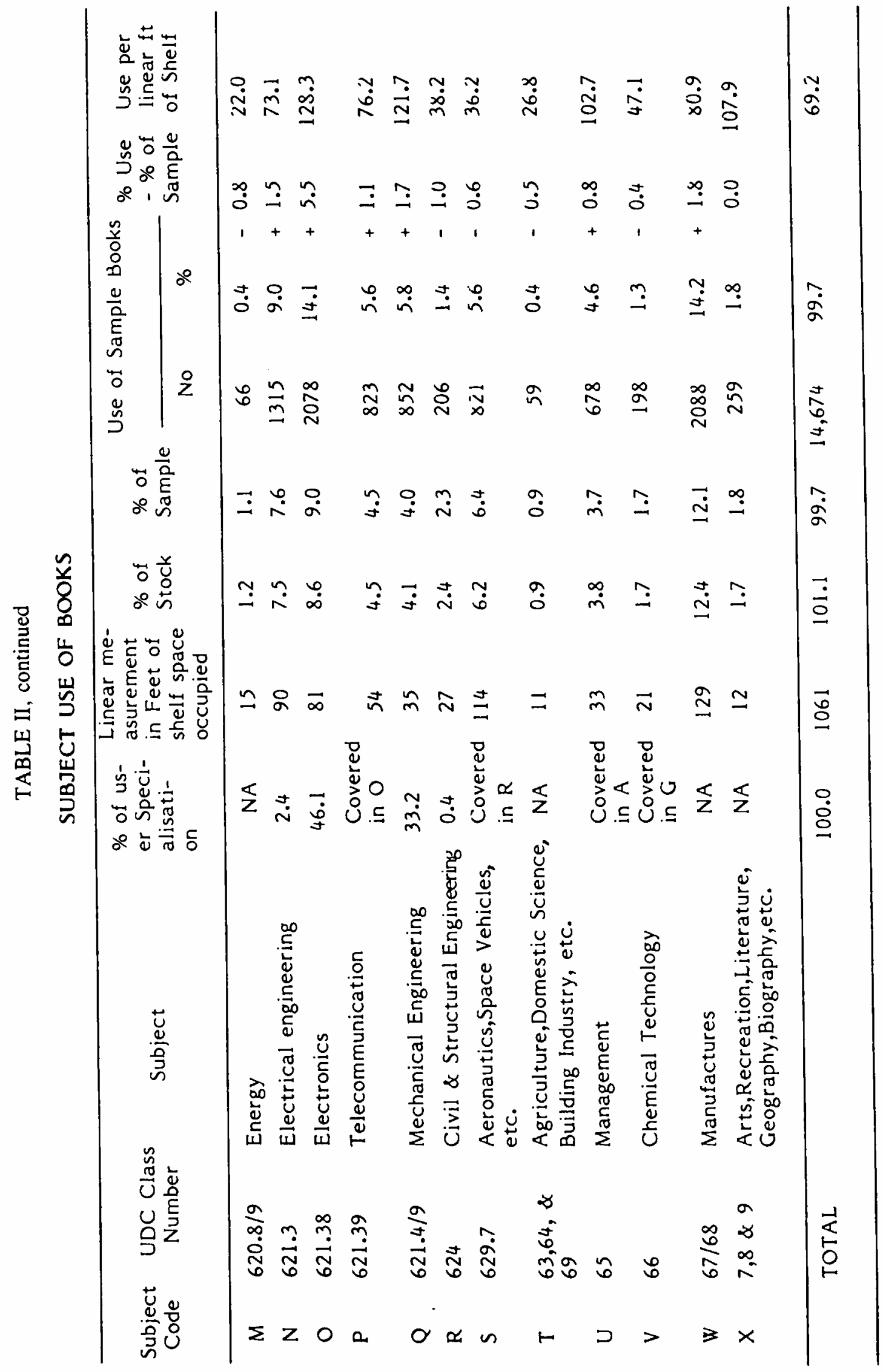


Subject and longitudinal use of books by Indian space technologists

TABLE III

LEAST AND HIGHEST USED BOOKS BY SUBJECT

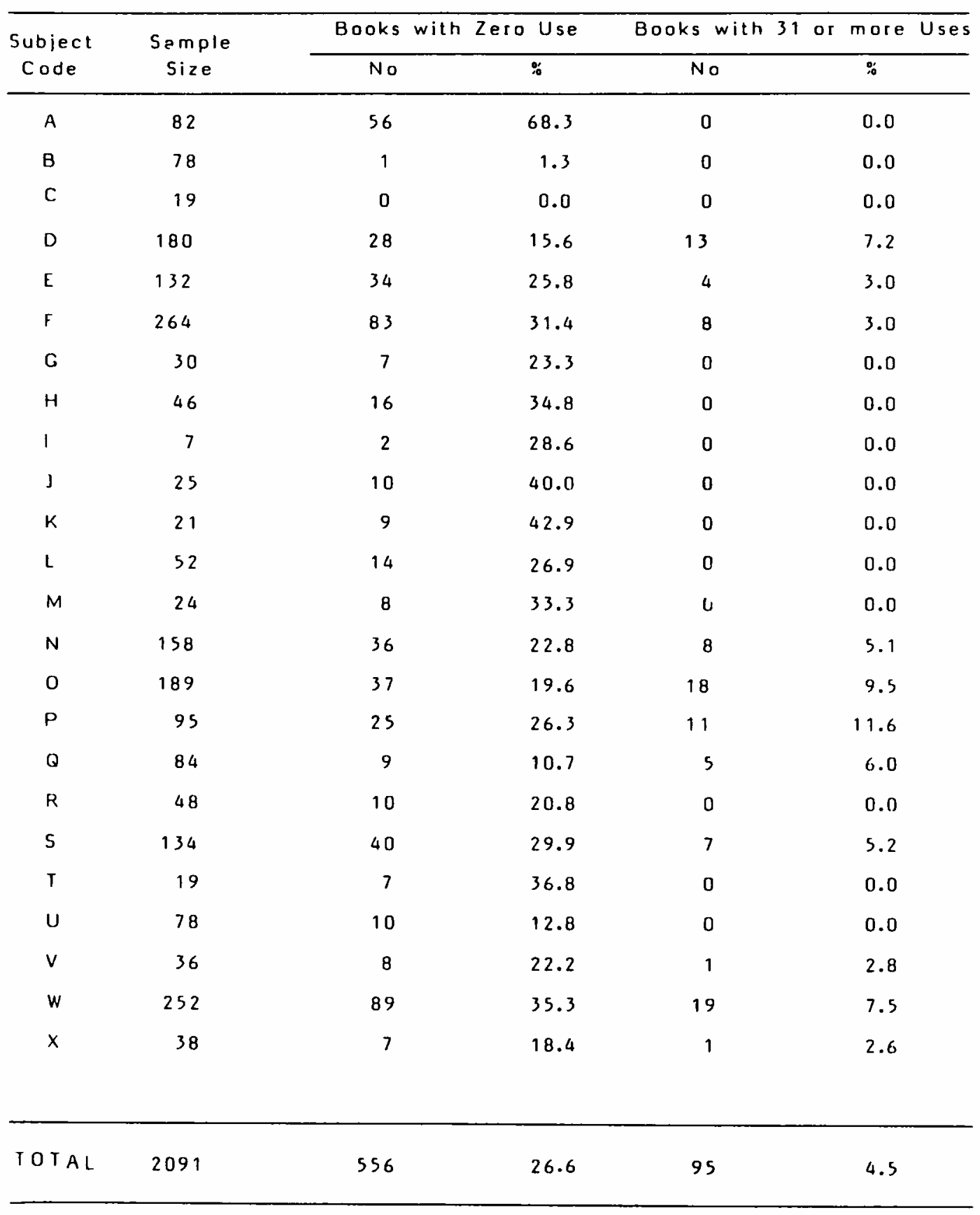


Subject and longitudinal use of books by Indian space technologists

TABLE IV

LONGITUDINAL USE OF BOOKS

\begin{tabular}{|c|c|c|c|c|c|c|}
\hline \multirow[b]{2}{*}{$\begin{array}{l}\text { Subject } \\
\text { Code }\end{array}$} & \multirow[b]{2}{*}{$\begin{array}{c}\because \text { of } \\
5 \text { a mple }\end{array}$} & \multicolumn{4}{|c|}{ Use of Sample Books } & \multirow{2}{*}{$\begin{array}{l}\% \text { of Use during } \\
\text { lest } 10 \text { months - } \\
\text { of Cumulative use } \\
\text { te., (4) - (6) }\end{array}$} \\
\hline & & \multicolumn{2}{|c|}{$\begin{array}{l}\text { During lest } \\
10 \text { months }\end{array}$} & \multicolumn{2}{|c|}{$\begin{array}{l}\text { Cumulative use } \\
\text { so fer \% }\end{array}$} & \\
\hline A & 3.9 & 15 & 0.5 & 104 & 0.7 & -0.2 \\
\hline B & 3.7 & 96 & 3.0 & 490 & 3.3 & -0.3 \\
\hline c & 0.9 & 20 & 0.6 & 146 & 1.0 & -0.4 \\
\hline D & 8.6 & 286 & 9.1 & 1575 & 10.7 & -1.6 \\
\hline$E$ & 6.3 & 100 & 3.2 & 840 & 5.7 & -2.5 \\
\hline$F$ & 12.6 & 278 & 8.8 & 1472 & 10.0 & -1.2 \\
\hline G & 1.4 & 15 & 0.5 & 90 & 0.6 & -0.1 \\
\hline$H$ & 2.2 & 11 & 0.3 & 113 & 0.8 & -0.5 \\
\hline 1 & 0.3 & 3 & 0.1 & 31 & 0.2 & -0.1 \\
\hline $\mathrm{J}$ & 1.2 & 19 & 0.6 & 68 & 0.5 & +0.1 \\
\hline$k$ & 1.0 & 36 & 1.1 & 121 & 0.8 & +0.3 \\
\hline L & 2.5 & 40 & 1.3 & 181 & 1.2 & +0.1 \\
\hline$M$ & 1.1 & 7 & 0.2 & 66 & 0.4 & -0.2 \\
\hline$N$ & 7.6 & 269 & 8.5 & 1315 & 9.0 & -0.5 \\
\hline 0 & 9.0 & 507 & 16.1 & 2078 & 14.1 & +2.0 \\
\hline$P$ & 4.5 & 167 & 5.3 & 823 & 5.6 & -0.3 \\
\hline$Q$ & 4.0 & 170 & 5.4 & 852 & 5.8 & -0.4 \\
\hline $\mathrm{R}$ & 2.3 & 33 & 0.9 & 206 & 1.4 & -0.5 \\
\hline$s$ & 6.4 & 207 & 6.6 & 821 & 5.6 & +1.0 \\
\hline$T$ & 0.9 & 11 & 0.3 & 59 & 0.4 & -0.1 \\
\hline$u$ & 3.7 & 104 & 3.3 & 678 & 4.6 & -1.3 \\
\hline$v$ & 1.7 & 39 & 1.2 & 198 & 1.3 & -0.1 \\
\hline w & 12.1 & 687 & 21.8 & 2088 & 14.2 & +7.6 \\
\hline$x$ & 1.8 & 38 & 1.2 & 259 & 1.8 & -0.6 \\
\hline TOTAL & 99.7 & 3158 & 99.9 & 14,674 & 99.7 & \\
\hline
\end{tabular}


Subject and longitudinal use of books by Indian space technologists

TABLE $V$

YEAR OF PUBLICATION OF BOOKS VS USE

\begin{tabular}{|c|c|c|c|c|c|}
\hline $\begin{array}{l}\text { Yeat of } \\
\text { Pub. }\end{array}$ & Sample Books & Covered & & ns & $\begin{array}{l}\text { Average Use } \\
\text { per Book }\end{array}$ \\
\hline & No & $\%$ & No & $\%$ & \\
\hline 83 & 1 & 0.0 & 0 & 0.0 & 0.00 \\
\hline 82 & 29 & 1.4 & 102 & 0.7 & 3.52 \\
\hline 81 & 76 & 3.6 & 268 & 1.8 & 3.53 \\
\hline 80 & 148 & 7.1 & 475 & 3.2 & 3.21 \\
\hline 79 & 232 & 11.1 & 1435 & 10.1 & 6.19 \\
\hline 78 & 248 & 11.9 & 1621 & 11.0 & 6.54 \\
\hline 77 & 232 & 11.1 & 1392 & 9.2 & 6.00 \\
\hline 76 & 176 & 8.4 & 1011 & 6.9 & 5.74 \\
\hline 75 & 116 & 5.5 & 921 & 6.3 & 7.94 \\
\hline 74 & 117 & 5.6 & 737 & 5.0 & 6.30 \\
\hline 73 & 95 & 4.5 & 673 & 4.6 & 7.00 \\
\hline 72 & 108 & 5.2 & 894 & 6.1 & 8.28 \\
\hline 71 & 96 & 4.6 & 759 & 5.2 & 7.91 \\
\hline $66-70$ & 258 & 12.3 & 1905 & 13.0 & 7.38 \\
\hline $61-65$ & 148 & 7.1 & 969 & 6.6 & 6.55 \\
\hline $56-60$ & 67 & 3.2 & 502 & 3.4 & 7.50 \\
\hline $51-55$ & 13 & 0.6 & 182 & 1.2 & 14.00 \\
\hline Upto 50 & 22 & 1.1 & 68 & 0.5 & 3.00 \\
\hline Error & -91 & -4.4 & +760 & +5.2 & - \\
\hline TOTAL & 2091 & 99.9 & 14674 & 100.3 & 7.01 \\
\hline
\end{tabular}


Subject and longitudinal use of books by Indian space technologists

TABLE VI

MODE YEAR OF PUBLICATION OF BOOKS

IN DIFFERENT SUBJECT GROUPS

\begin{tabular}{|c|c|c|}
\hline $\begin{array}{l}\text { Mode year of } \\
\text { Publicetion }\end{array}$ & Subiect Codes & Subjects \\
\hline 72 & D & Mathematics \\
\hline 74 & H & Geology, Meteorology, etc. \\
\hline 75 & $R *$ & Civil and Structurel engineering \\
\hline 76 & $J, P$ & $\begin{array}{l}\text { Medical sciences, Health and } \\
\text { Safety; Telecommunication }\end{array}$ \\
\hline 77 & $A, B^{*}, C, K, L, M, U$ & $\begin{array}{l}\text { Generalities; Philosophy, Religion, } \\
\text { etc.; Natural sciences; Engineering } \\
\text { and Technology; Material science; } \\
\text { Energy; Management. }\end{array}$ \\
\hline 78 & $\begin{array}{l}E, F, G^{*}, N, T, V \\
W, x\end{array}$ & $\begin{array}{l}\text { Astronomy, Astrophysics, etc.; } \\
\text { Physics; Chemistry; Paleontology, } \\
\text { etc; Electrical Engineering; Agri- } \\
\text { culture; Domestic science, etc., } \\
\text { Chemical Technology; Manufactures; } \\
\text { Arts, Recreation, etc. }\end{array}$ \\
\hline 79 & $B^{*}, 1,0, Q, S$ & $\begin{array}{l}\text { Philosophy, Religion etc; Applied } \\
\text { science and Technology; Electronics, } \\
\text { Mechanical Engineering, Aeroneu- } \\
\text { tics, Spece vehicles, etc. }\end{array}$ \\
\hline 80 & $G *, R *$ & $\begin{array}{l}\text { Chemistry, Paleontology, etc; } \\
\text { Civil and Structural engineering }\end{array}$ \\
\hline
\end{tabular}

* Biomodel distributions 
Subject and longitudinal use of books by Indian space technologists

TABLE VII

YEAR OF ACQUISITION OF BOOKS VS USE

\begin{tabular}{|c|c|c|c|c|c|c|c|}
\hline \multirow{2}{*}{$\begin{array}{l}\text { Yeat of } \\
\text { Acq. }\end{array}$} & \multicolumn{2}{|c|}{ Totel Acquited } & \multicolumn{2}{|c|}{ Sample books } & \multicolumn{2}{|c|}{ Lent out Use } & \multirow{2}{*}{$\begin{array}{l}\text { Average } \\
\text { Use per } \\
\text { Book }\end{array}$} \\
\hline & No & $\%$ & No & $\%$ & $N_{0}$ & $\%$ & \\
\hline 83 & 1286 & 10.1 & 26 & 1.2 & 57 & 0.4 & 2.19 \\
\hline 82 & 1477 & 11.6 & 231 & 11.0 & 900 & 6.1 & 3.90 \\
\hline 81 & 944 & 7.4 & 188 & 9.0 & 892 & 6.1 & 4.96 \\
\hline 80 & 1401 & 11.0 & 290 & 13.9 & 1762 & 12.0 & 6.26 \\
\hline 79 & 1898 & 14.9 & 378 & 18.1 & 2718 & 18.5 & 7.61 \\
\hline 78 & 1980 & 15.5 & 397 & 19.0 & 2210 & 15.1 & 6.38 \\
\hline 77 & 1032 & 8.1 & 180 & 8.6 & 1509 & 10.3 & 8.54 \\
\hline 76 & 509 & 4.0 & 68 & 3.3 & 685 & 4.7 & 11.96 \\
\hline 75 & 413 & 3.2 & 82 & 3.9 & 737 & 5.0 & 10.18 \\
\hline 74 & 578 & 4.5 & 90 & 4.3 & 889 & 6.1 & 9.93 \\
\hline 73 & 1230 & 9.6 & 267 & 12.8 & 2879 & 19.6 & 10.75 \\
\hline Error & 0 & 0.0 & -106 & -5.1 & -564 & -3.8 & - \\
\hline TOTAL & 12748 & 99.9 & 2091 & 100.0 & 14674 & 100.1 & 7.01 \\
\hline
\end{tabular}

The Serials Librarian 10 (3) Spring 1986: 77-93.

\section{About the Author}

Dr. M. S. Sridhar is a post graduate in Mathematics and Business Management and a Doctorate in Library and Information Science. He is in the profession for last 36 years. Since 1978, he is heading the Library and Documentation Division of ISRO Satellite Centre, Bangalore. Earlier he has worked in the libraries of National Aeronautical Laboratory (Bangalore), Indian Institute of Management (Bangalore) and University of Mysore. Dr. Sridhar has published 4 books, 83 research articles, 22 conferences papers, written 19 course materials for BLIS and MLIS, made over 25 seminar presentations and contributed 5 chapters to books.

E-mail: sridharmirle@yahoo.com, mirlesridhar@gmail.com, sridhar@isac.gov.in ; Phone: 91-8025084451; Fax: 91-80-25084476. 